\title{
Microarray-based bioinformatics analysis of the prospective target gene network of key miRNAs influenced by long non-coding RNA PVT1 in HCC
}

\author{
YU ZHANG $^{1 *}$, WEI-JIA MO ${ }^{1 *}$, XIAO WANG ${ }^{2}$, TONG-TONG ZHANG ${ }^{1}$, YUAN QIN $^{1}$, \\ HAN-LIN WANG ${ }^{1}$, GANG CHEN $^{1}$, DAN-MING WEI ${ }^{1}$ and YI-WU DANG ${ }^{1}$ \\ ${ }^{1}$ Department of Pathology, First Affiliated Hospital of Guangxi Medical University, Nanning, \\ Guangxi Zhuang Autonomous Region 530021; ${ }^{2}$ Department of Orthopedics, \\ Shandong Provincial Hospital Affiliated to Shandong University, Jinan, Shandong 250012, P.R. China
}

Received September 26, 2017; Accepted April 17, 2018

DOI: $10.3892 /$ or.2018.6410

\begin{abstract}
The long non-coding RNA (lncRNA) PVT1 plays vital roles in the tumorigenesis and development of various types of cancer. However, the potential expression profiling, functions and pathways of PVT1 in HCC remain unknown. PVT1 was knocked down in SMMC-7721 cells, and a miRNA microarray analysis was performed to detect the differentially expressed miRNAs. Twelve target prediction algorithms were used to predict the underlying targets of these differentially expressed miRNAs. Bioinformatics analysis was performed to explore the underlying functions, pathways and networks of the targeted genes. Furthermore, the relationship between PVT1 and the clinical parameters in HCC was confirmed based on the original data in the TCGA database. Among the differentially expressed miRNAs, the top two upregulated and
\end{abstract}

Correspondence to: Dr Dan-Ming Wei or Dr Yi-Wu Dang, Department of Pathology, First Affiliated Hospital of Guangxi Medical University, 6 Shuangyong Road, Nanning, Guangxi Zhuang Autonomous Region 530021, P.R. China

E-mail: danmingwei08@163.com

E-mail: dangyiwu@126.com

*Contributed equally

Abbreviations: HCC, hepatocellular carcinoma; lncRNAs, long non-coding RNAs; TCGA, The Cancer Genome Atlas; MEM, Multi Experiment Matrix; GO, Gene Ontology; KEGG, Kyoto Encyclopedia of Genes and Genomes; PPI, protein-protein interactions; ROC, receiver operating characteristic; BP, biological process; $\mathrm{CC}$, cellular component; $\mathrm{MF}$, molecular function; FDR, false discovery rate; AUC, area under curve; HBV, hepatitis B virus; HCV, hepatitis C virus; DMEM, Dulbecco's modified Eagle's medium; FBS, fetal bovine serum; DAVID, Database for Annotation, Visualization and Integrated Discovery; STRING, Search Tool for the Retrieval of Interacting Genes; ANOVA, one-way analysis of variance; mean $\pm \mathrm{SD}$, mean \pm standard deviation; $\mathrm{FC}$, fold-change

Key words: PVT1, HCC, miRNAs, GO, KEGG, PPI downregulated miRNAs were selected for further analysis based on the false discovery rate (FDR), fold-change (FC) and P-values. Based on the TCGA database, PVT1 was obviously highly expressed in HCC, and a statistically higher PVT1 expression was found for sex (male), ethnicity (Asian) and pathological grade $(\mathrm{G} 3+\mathrm{G} 4)$ compared to the control groups $(\mathrm{P}<0.05)$. Furthermore, Gene Ontology $(\mathrm{GO})$ analysis revealed that the target genes were involved in complex cellular pathways, such as the macromolecule biosynthetic process, compound metabolic process, and transcription. Kyoto Encyclopedia of Genes and Genomes (KEGG) analysis revealed that the MAPK and Wnt signaling pathways may be correlated with the regulation of the four candidate miRNAs. The results therefore provide significant information on the differentially expressed miRNAs associated with PVT1 in $\mathrm{HCC}$, and we hypothesized that PVT1 may play vital roles in HCC by regulating different miRNAs or target gene expression (particularly MAPK8) via the MAPK or Wnt signaling pathways. Thus, further investigation of the molecular mechanism of PVT1 in HCC is needed.

\section{Introduction}

Hepatocellular carcinoma (HCC) remains one of the main malignancies worldwide with a poor 5-year survival rate (1-4). Generally, patients are diagnosed with $\mathrm{HCC}$ at an advanced stage, and a large number of HCC patients show intrahepatic metastasis and postoperative recurrence (5). In the Chinese population, the development of $\mathrm{HCC}$ has been associated with the hepatitis $\mathrm{B}$ virus (HBV) and hepatitis $\mathrm{C}$ virus (HCV) infections in most patients (6). The long-term symptoms of inflammation, chronic hepatitis and cirrhosis contribute to the virus-initiated tumorigenic process $(7,8)$. For the treatment of $\mathrm{HCC}$, liver transplantation or tumor resection is always the most effective treatment. Furthermore, the high rate of metastasis or postsurgical recurrence remains an obstacle to a better prognosis of HCC patients $(9,10)$. Thus, it is imperative to explore the mechanism of HCC, which may lead to novel insights for the diagnosis and treatment of HCC patients. 
Long non-coding RNAs (lncRNAs) include the recently identified class of non-protein coding RNA transcripts of 200 nucleotides to $100 \mathrm{~kb}$ in length (11-13). Accumulating evidence has demonstrated that lncRNAs may contribute to various biological processes, including proliferation, apoptosis, invasion and metastasis (14-16). However, the particular mechanisms of many lncRNAs remain vague. lncRNA PVT1 is located on chromosomal region $8 \mathrm{q} 24$, which is a well-known cancer-related region (17). Previous studies have confirmed that the overexpression of PVT1 accelerates the development and progression of cancer and reduces the chemosensitivity of cancer patients. Although, compared with normal liver tissues, PVT1 showed a high expression in HCC, improved proliferation and predicted recurrence, the precise functions and mechanism of PVT1 in HCC remain to be elucidated (18-20).

miRNAs refer to small non-coding RNAs with nearly 20 nucleotides. Recent studies have confirmed that lncRNAs can affect HCC via combining the expression of miRNAs $(21,22)$. For example, Liu et al (21) found that IncRNA FTX inhibited the proliferation and metastasis of HCC by binding to miR-374a. Zhu et al (22) revealed that IncRNA LINC00052 inhibited the invasion and migration of HCC by binding to miR-452-5p. Therefore, it is of great significance to further explore the miRNA expression profile associated with lncRNA in $\mathrm{HCC}$ in order to identify novel therapeutic strategies.

In the present study, we validated the differential PVT1 expression in normal liver and HCC. Furthermore, we combined the miRNA expression profile after silencing PVT1 expression and miRNA target prediction algorithms to explore the underlying target genes related to PVT1 in HCC. Bioinformatics analysis, involving Gene Ontology (GO), Kyoto Encyclopedia of Genes and Genomes (KEGG), protein-protein interactions (PPIs) and network analyses, was utilized to explore the underlying functions, pathways and networks of the target genes (23-26). Furthermore, the relationship between PVT1 and the clinical parameters in HCC was confirmed based on the original data in the TCGA database. A flow chart of the present study is shown in Fig. 1.

\section{Materials and methods}

Cell culture and siRNA transfection. Human HCC cells (SMMC-7721) were obtained from the American Type Culture Collection (ATCC), and the SMMC-7721 cells were cultured in Dulbecco's modified Eagle's medium (DMEM) supplemented with $1 \%$ penicillin/streptomycin and $10 \%$ fetal bovine serum (FBS) at $37^{\circ} \mathrm{C}$ in a humidified incubator with $5 \% \mathrm{CO}_{2}$. The Lenti-siRNA vector of PVT1 was produced by GeneChem (Shanghai, China) (sense, 5'-CCCAACAGGAGG ACAGCUUTT-3' and antisense, 5'-AAGCUGUCCUCCUGU UGGGTT-3'). siRNA vectors of PVT1 were transfected into HCC cells according to the manufacturer's protocol.

miRNA microarray analysis. The sample analysis and miRNA microarray hybridization were completed by Kangchen Bio-tech (Shanghai, China). Briefly, miRNA labeling was performed using the miRCURY ${ }^{\mathrm{TM}}$ Array Power Labeling kit (cat. no. 208032-A; Exiqon, Vedbaek, Denmark). Then, the labeled sample was combined with $2 \mathrm{X}$ Hybridization buffer (Phalanx Hyb). Assembly and miRCURY ${ }^{\mathrm{TM}}$ Array, was used for miRNA array hybridization. miRNA array scanning and analysis were applied via Axon GenePix 4000B microarray scanner and GenePix pro V6.0 software (Molecular Devices, LLC, Sunnyvale, CA, USA). Differentially expressed miRNAs between PVT1 RNAi and the control groups were identified when fold-change (FC) was $\geq 2$ or $\leq 0.5$, and false discovery rate $(\mathrm{FDR})<1$ and $\mathrm{P}<0.05$.

Validation of the expression of PVT1 in HCC. The TCGA database (http://cancergenome.nih.gov/) is a collection of DNA methylation, RNA-Seq, miRNA-seq, SNP array and exome sequencing $(27,28)$. TCGA can also be used to further explore the expression of complicated cancer genomics and clinical parameters. In the present study, RNA-Seq data of HCC cases, which were calculated on the IlluminaHiSeq RNA-Seq platform, were obtained from the TCGA data portal (https://tcga-data.nci.nih.gov/tcga/), containing $374 \mathrm{HCC}$ cases and 50 adjacent normal liver cases up to July 10, 2017. The original expression data of PVT1 were exhibited as reads per million (RPM) and the expression level of PVT1 was normalized by the Deseq package of $\mathrm{R}$ language. Prior to applying further analyses, we log transformed the original expression data for PVT1. The difference expression of PVT1 in various clinicopathological parameters in $\mathrm{HCC}$ was acknowledged based on the data from the TCGA database. The diagnostic value of PVT1 was evaluated using the receiver operating characteristic (ROC) curve. Additionally, the genetic alteration of PVT1 in HCC was investigated based on TCGA. Furthermore, Oncomine (https://www.oncomine.org/) and GEPIA (http://gepia.cancer-pku.cn/) databases were assisted to validate PVT1 expression in $\operatorname{HCC}(29,30)$.

Target prediction and functional analysis. Twelve target prediction algorithms were used to predict the probable target genes of miRNAs. The 12 corresponding prediction algorithms were miRWalk (http://zmf.umm.uni-heidelberg. de/apps/zmf/mirwalk2/), miRanda (http://www.microrna. org), mirBridge (http://mirsystem.cgm.ntu.edu.tw/), DIANA microT v4 (http://diana.imis.athena-innovation.gr/), miRMap (http://mirmap.ezlab.org/), miRDB (http://www.mirdb.org/), miRNAMap (http://mirnamap.mbc.nctu.edu.tw/), RNA22 (https://cm.jefferson.edu/), Pictar2 (https://www.mdc-berlin. de/), RNAhybrid (https://bibiserv.cebitec.uni-bielefeld. de/), PITA (https://genie.weizmann.ac.il/), and TargetScan (http://www.targetscan.org/), and the overlapping target genes were identified via Venn diagrams (http://bioinformatics.psb. ugent.be/webtools/Venn/). In addition, the HPA (http://www. proteinatlas.org) was used to explore the protein expression of target genes in HCC and normal liver tissues.

To further consider the potential functions, pathways and networks of these target genes, bioinformatics analyses (GO, KEGG and network analyses) were performed $(31,32)$. In this process, Database for Annotation, Visualization and Integrated Discovery (DAVID: available online: http://david. abcc.ncifcrf.gov/) was utilized to perform GO and KEGG analyses, and biological process (BP), cellular component (CC) and molecular function (MF) categories were derived from the GO analysis. Additionally, Cytoscape (version 2.8, http://cytoscape.org) was applied to construct the functional network. 


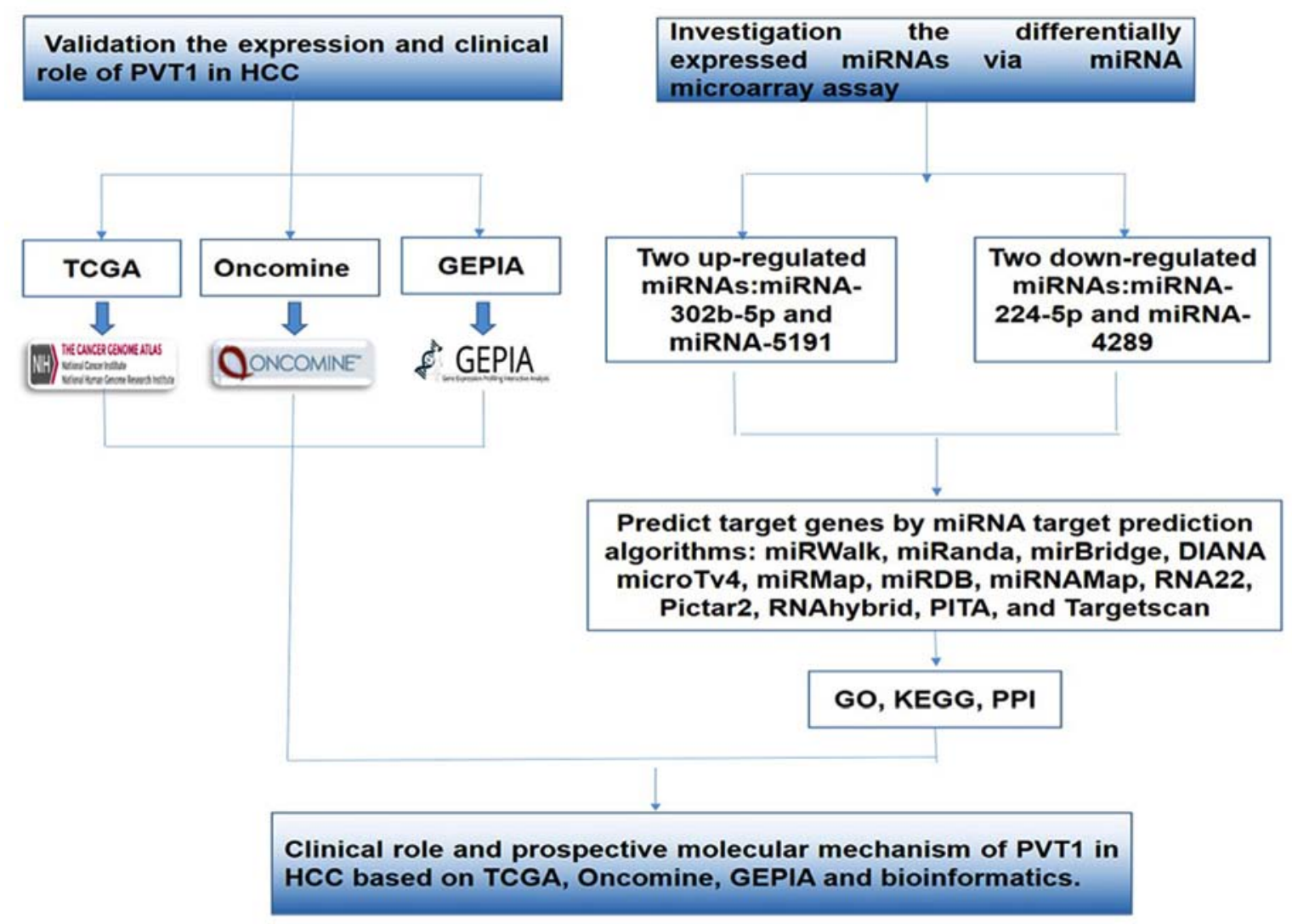

Figure 1. A flow chart of the present study.

Construction of protein-protein interaction (PPI) network. The interaction pairs of the overlapped target genes were researched by Search Tool for the Retrieval of Interacting Genes (STRING; version 9.0, http://string-db.org) (33). The STRING database provides a worldwide perspective for as many animals and mammals as feasible. The predicted and acknowledged interactions are unified and scored. The interaction pairs in PPI network were selected when the combined score was $>0.4$.

Statistical analysis. SPSS 22.0 software (IBM Corp., Armonk, NY, USA) was used for the statistical analysis. Data were expressed as mean \pm standard deviation (SD). Differences in the expression of PVT1 in HCC and normal liver and various clinicopathological parameters were estimated by the Student's t-test. The comparison between different subgroups was performed by one-way analysis of variance (ANOVA). Kaplan-Meier curves were used to detect the relationship between the PVT1 expression and patient survival in HCC. In addition, the ROC curve was used to predict the clinical diagnostic value of PVT1, which was statistically significant when $\mathrm{P}<0.05$ (two-sided).

\section{Results}

miRNA profiling associated with lncRNA PVT1. The transfection efficiency was $\sim 90 \%$, and the knockdown efficiency of PVT1 in SMMC-7721 cells was $>75 \%$ as detected by RT-qPCR (data not shown). Next, a miRNA microarray assay was applied to detect the differentially expressed
Table I. The top 2 upregulated and top 2 downregulated miRNAs.

\begin{tabular}{lccc}
\hline Name & Fold-change & P-value & FDR \\
\hline Upregulated miRNAs & & & \\
miR-302b-5p & 2.832 & 0.020 & 0.441 \\
miR-5191 & 2.477 & 0.013 & 0.409 \\
Downregulated miRNAs & & & \\
miR-224-5p & 0.372 & 0.009 & 0.398 \\
miR-4289 & 0.453 & 0.002 & 0.349 \\
miR-UL22A-5p & 0.040 & 0.001 & 0.349 \\
miR-548aa/miR-548t-3p & 0.455 & 0.003 & 0.371 \\
miR-544b & 0.076 & 0.006 & 0.379 \\
miR-374c-3p & 0.465 & 0.010 & 0.398 \\
miR-5009-5p & 0.379 & 0.012 & 0.407 \\
miR-138-1-3p & 0.392 & 0.033 & 0.441 \\
miR-154-5p & 0.360 & 0.036 & 0.441 \\
miR-5003-5p & 0.475 & 0.038 & 0.441 \\
miR-195-5p & 0.421 & 0.043 & 0.441 \\
miR-3131 & 0.354 & 0.049 & 0.441 \\
\hline
\end{tabular}

miRNAs between PVT1 RNAi and the control groups. We found that 2 miRNAs were upregulated, and 12 miRNAs were downregulated in response to PVT1 knockdown. A summary of the differentially expressed miRNAs is shown in Fig. 2 and Table I. The top 2 upregulated (miR-302b-5p, miR-5191) 

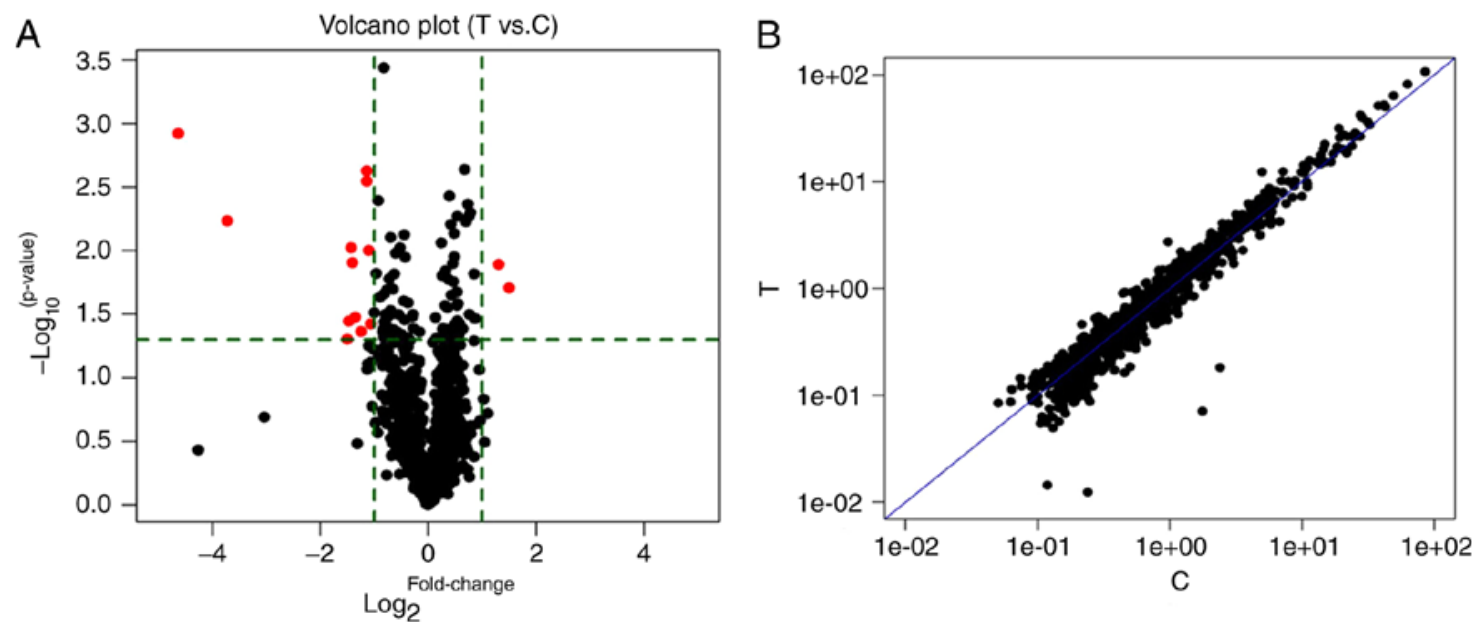

Figure 2. miRNA clip after PVT1 knock-down in HCC. (A) Volcano plots of miRNAs. Volcano plots were constructed by fold-change and P-values. The vertical lines correspond to P-values, and the horizontal lines represent $\log 2$ (fold-change) upregulation and downregulation. The red points indicate the significantly differentially expressed miRNAs. (B) Scatter plot of miRNAs. Scatter plots were generated to assess variations in miRNA expression. The values corresponding to the $\mathrm{x}$-axes and $\mathrm{y}$-axes are the normalized signal values.

Table II. Differential expression of PVT1 of other clinicopathological parameters in HCC based on TCGA.

\begin{tabular}{|c|c|c|c|c|}
\hline \multirow[b]{2}{*}{ Clinicopathological parameters } & \multirow[b]{2}{*}{$\mathrm{N}$} & \multicolumn{2}{|c|}{ PVT1 expression } & \multirow[b]{2}{*}{ P-value } \\
\hline & & Mean \pm SD & $\mathrm{T}$ & \\
\hline \multicolumn{5}{|l|}{ Tissues } \\
\hline Normal liver & 50 & $5.489 \pm 0.095$ & 12.43 & $<0.001$ \\
\hline $\mathrm{HCC}$ & 374 & $7.044 \pm 0.082$ & & \\
\hline \multicolumn{5}{|l|}{ Age (years) } \\
\hline$<60$ & 169 & $7.078 \pm 1.493$ & 0.305 & 0.761 \\
\hline$\geq 60$ & 201 & $7.027 \pm 1.651$ & & \\
\hline \multicolumn{5}{|l|}{ Sex } \\
\hline Male & 250 & $7.206 \pm 1.624$ & 2.631 & 0.009 \\
\hline Female & 121 & $6.749 \pm 1.447$ & & \\
\hline \multicolumn{5}{|l|}{ Race } \\
\hline White & 184 & $6.811 \pm 1.525$ & $\mathrm{~F}=5.436$ & 0.005 \\
\hline Black & 17 & $6.642 \pm 1.575$ & & \\
\hline Asian & 158 & $7.340 \pm 1.604$ & & \\
\hline \multicolumn{5}{|l|}{$\mathrm{T}$ (tumor) } \\
\hline $\mathrm{T} 1+\mathrm{T} 2$ & 275 & $7.045 \pm 1.516$ & -0.308 & 0.758 \\
\hline $\mathrm{T} 3+\mathrm{T} 4$ & 93 & $7.104 \pm 1.779$ & & \\
\hline \multicolumn{5}{|l|}{ Stage } \\
\hline $\mathrm{I}+\mathrm{II}$ & 257 & $7.083 \pm 1.534$ & 0.106 & 0.916 \\
\hline $\mathrm{III}+\mathrm{IV}$ & 90 & $7.062 \pm 1.750$ & & \\
\hline \multicolumn{5}{|l|}{ Pathological grade } \\
\hline $\mathrm{G} 1+\mathrm{G} 2$ & 232 & $6.874 \pm 1.491$ & -2.970 & 0.003 \\
\hline $\mathrm{G} 3+\mathrm{G} 4$ & 134 & $7.382 \pm 1.708$ & & \\
\hline
\end{tabular}

and downregulated miRNAs (miR-224-5p, miR-4289) were finally selected as the most significant differentially expressed miRNAs due to the FC, FDR and P-values. Significance was determined via an $\mathrm{FC} \geq 2$ or $\leq 0.5, \mathrm{FDR}<1$ and $\mathrm{P}<0.05$ was applied (34). We focused on the top two upregulated and downregulated miRNAs to improve the accuracy and stability of the results. The targets of the top dysregulated miRNAs may play key regulation roles in PVT1-related HCC. 


\section{A Altered in $105(24 \%)$ of 440 sequenced cases/patients (440 total) Total mutations

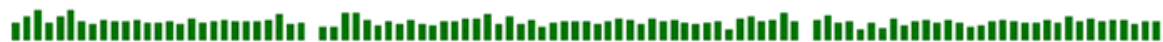 \\ PVT : 24\% ||||||||||||||||||||||||||||||||||||||||||||||||||||||||||||||||||||||||| ||

$\begin{array}{ll}\text { Genetic alteration I Amplification I Deep deletion I mRNA upregulation } \\ \text { Total mutations } & 1290\end{array}$
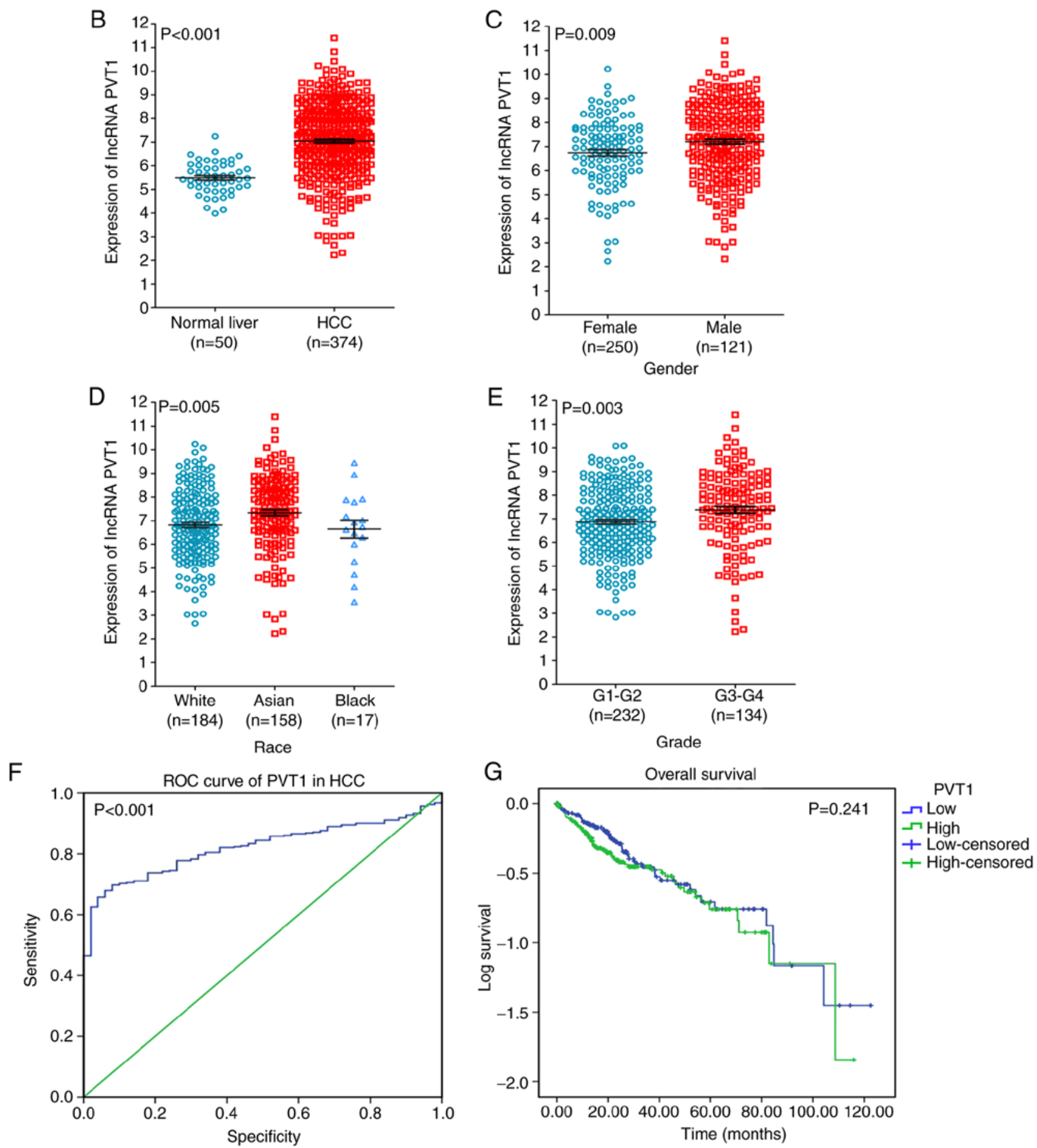

Figure 3. Clinical significance of lncRNA PVT1 in HCC based on the TCGA database. (A) The genetic alteration of PVT1 in HCC, (B) differential expression of PVT1 between HCC and non-cancerous liver tissue, (C) differential expression of PVT1 in male vs. female, (D) white vs. yellow vs. black, (E) G1, G2 vs. G3, G4, (F) ROC curve of PVT1 in HCC, and (G) Kaplan-Meier curves of PVT1 expression in HCC.

Validation of the expression of PVT1 in HCC. Based on TCGA, 24\% cases of PVT1 in HCC were found, which contained amplification, deep deletion and mRNA upregulation (Fig. 3A). To demonstrate the vital role of PVT1 in HCC, a 

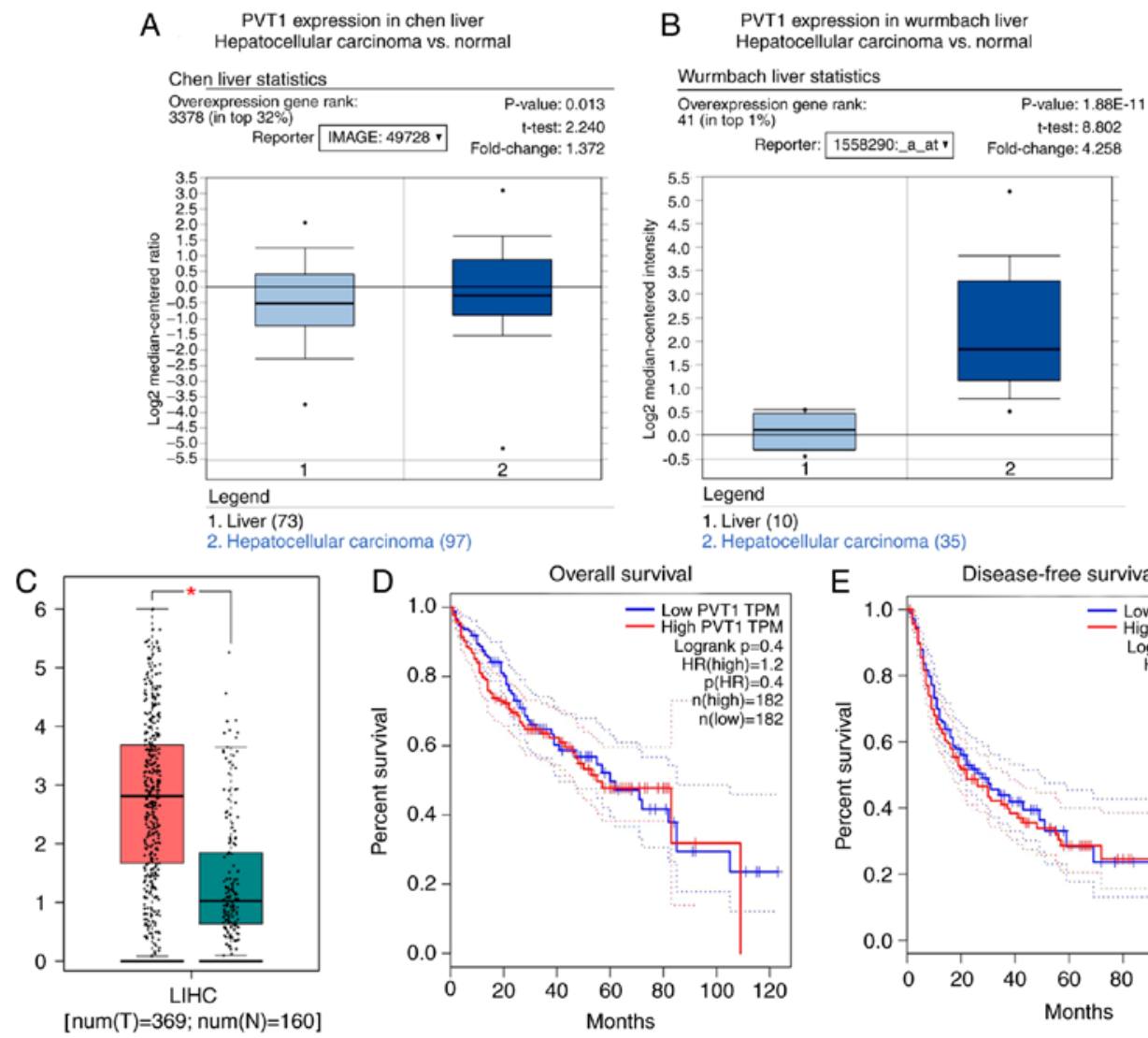

2. Hepatocellular carcinoma (35)
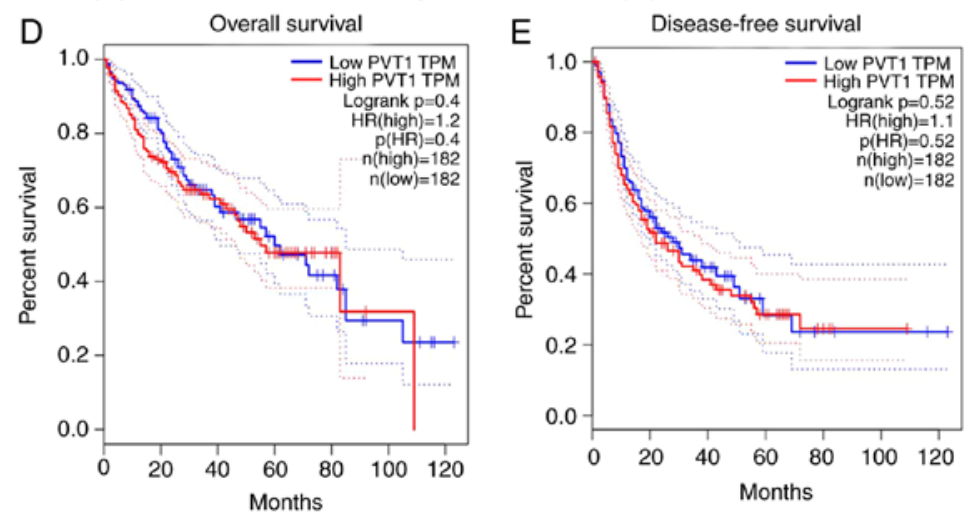

Figure 4. Validation of PVT1 expression in HCC. (A) Validation of PVT1 expression in the cohort of Chen Liver from Oncomine. Normal liver tissues (n=73) and hepatocellular carcinoma tissues ( $\mathrm{n}=97$ ) were included. (B) Validation of PVT1 expression in the cohort of Wurmbach Liver from Oncomine. Normal liver tissues $(n=10)$ and hepatocellular carcinoma tissues $(n=35)$ were included. (C) Normal liver tissues $(n=160)$ and HCC tissues $(n=369)$ were included based on the GEPIA database. (D) Overall survival of PVT1 expression in HCC based on the GEPIA database. (E) Disease-free survival of PVT1 expression in HCC based on the GEPIA database.

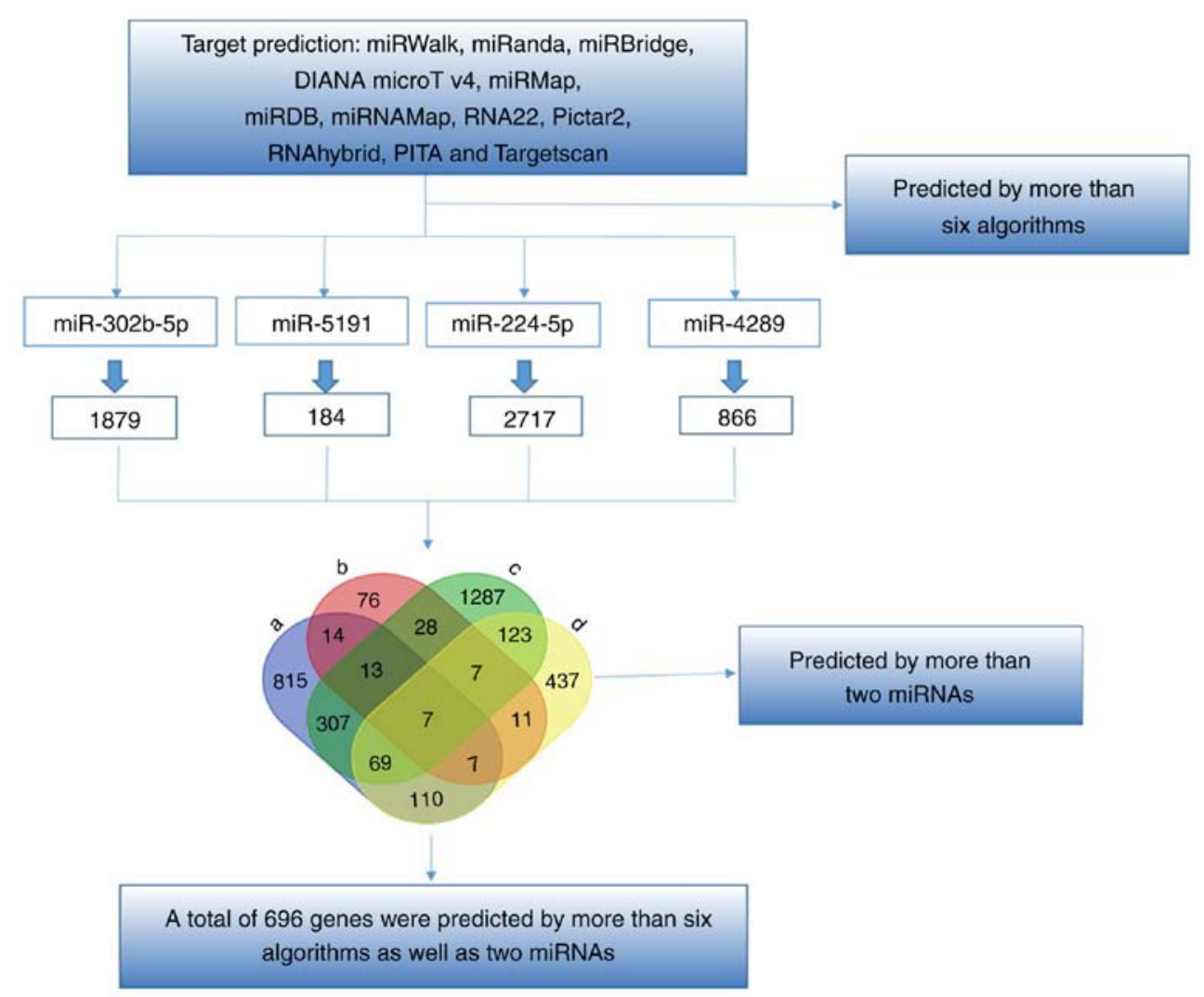

Figure 5. The procedure to achieve 696 genes. a, miR-302b-5p; b, miR-5191; c, miR-224-5p; and d, miR-4289. 
Table III. Top 10 enrichment GO terms (BP, CC and MF) for the target genes of miRNAs.

\begin{tabular}{|c|c|c|c|c|c|}
\hline GO ID & Term & Ontology & Count & $\begin{array}{l}\text { Fold } \\
\text { enrichment }\end{array}$ & P-value \\
\hline GO:0010557 & Positive regulation of macromolecule biosynthetic process & $\mathrm{BP}$ & 53 & 2.197 & $1.24121 \mathrm{E}-07$ \\
\hline GO:0051173 & Positive regulation of nitrogen compound metabolic process & $\mathrm{BP}$ & 52 & 2.189 & $1.89479 \mathrm{E}-07$ \\
\hline GO:0045941 & Positive regulation of transcription & $\mathrm{BP}$ & 47 & 2.259 & $3.37814 \mathrm{E}-07$ \\
\hline GO:0009891 & Positive regulation of biosynthetic process & $\mathrm{BP}$ & 54 & 2.106 & 3.51213E-07 \\
\hline GO:0045893 & Positive regulation of transcription, DNA-dependent & $\mathrm{BP}$ & 42 & 2.387 & $3.84168 \mathrm{E}-07$ \\
\hline GO:0045935 & $\begin{array}{l}\text { Positive regulation of nucleobase, nucleoside, nucleotide } \\
\text { and nucleic acid metabolic process }\end{array}$ & $\mathrm{BP}$ & 50 & 2.172 & $4.265 \mathrm{E}-07$ \\
\hline GO:0051254 & Positive regulation of RNA metabolic process & $\mathrm{BP}$ & 42 & 2.367 & 4.81533E-07 \\
\hline GO:0031328 & Positive regulation of cellular biosynthetic process & $\mathrm{BP}$ & 53 & 2.098 & $5.24515 \mathrm{E}-07$ \\
\hline GO:0010628 & Positive regulation of gene expression & $\mathrm{BP}$ & 47 & 2.193 & 7.8235E-07 \\
\hline GO:0010604 & Positive regulation of macromolecule metabolic process & $\mathrm{BP}$ & 60 & 1.898 & $2.2026 \mathrm{E}-06$ \\
\hline GO:0005635 & Nuclear envelope & $\mathrm{CC}$ & 21 & 2.976 & $2.61292 \mathrm{E}-05$ \\
\hline GO:0030424 & Axon & $\mathrm{CC}$ & 18 & 3.287 & $3.2788 \mathrm{E}-05$ \\
\hline GO:0030426 & Growth cone & $\mathrm{CC}$ & 10 & 5.380 & $8.24587 \mathrm{E}-05$ \\
\hline GO:0030427 & Site of polarized growth & $\mathrm{CC}$ & 10 & 5.282 & 9.56427E-05 \\
\hline GO:0045202 & Synapse & $\mathrm{CC}$ & 28 & 2.291 & $9.57691 \mathrm{E}-05$ \\
\hline GO:0043005 & Neuron projection & $\mathrm{CC}$ & 27 & 2.293 & 0.0001 \\
\hline GO:0031965 & Nuclear membrane & $\mathrm{CC}$ & 11 & 4.377 & 0.0002 \\
\hline GO:0016010 & Dystrophin-associated glycoprotein complex & $\mathrm{CC}$ & 6 & 10.253 & 0.0002 \\
\hline GO:0031252 & Cell leading edge & $\mathrm{CC}$ & 15 & 3.158 & 0.0003 \\
\hline GO:0044459 & Plasma membrane part & $\mathrm{CC}$ & 105 & 1.385 & 0.0003 \\
\hline GO:0003700 & Transcription factor activity & MF & 71 & 1.857 & 4.45E-07 \\
\hline GO:0030528 & Transcription regulator activity & MF & 95 & 1.603 & $2.72 \mathrm{E}-06$ \\
\hline GO:0043565 & Sequence-specific DNA binding & MF & 45 & 1.891 & $5.87 \mathrm{E}-05$ \\
\hline GO:0008092 & Cytoskeletal protein binding & MF & 36 & 1.822 & 0.0007 \\
\hline GO:0016563 & Transcription activator activity & MF & 31 & 1.929 & 0.0007 \\
\hline GO:0051015 & Actin filament binding & MF & 9 & 4.331 & 0.0010 \\
\hline GO:0003779 & Actin binding & MF & 26 & 2.034 & 0.0010 \\
\hline GO:0003702 & RNA polymerase II transcription factor activity & MF & 20 & 2.091 & 0.0033 \\
\hline GO:0005127 & Ciliary neurotrophic factor receptor binding & MF & 3 & 25.507 & 0.0045 \\
\hline GO:0019899 & Enzyme binding & MF & 34 & 1.658 & 0.0047 \\
\hline
\end{tabular}

GO, Gene Ontology; BP, biological process; CC, cellular component; MF, molecular function.

clinical study was performed using the original data in TCGA. The results showed the obvious high expression of PVT1 in HCC compared to that in normal liver tissues $(\mathrm{P}<0.001$, Fig. 3B). Moreover, a statistically significant higher PVT1 expression was observed in sex (male), ethnicity (Asian) and pathological grade $(\mathrm{G} 3+\mathrm{G} 4)$ compared with that in the control groups $(\mathrm{P}<0.05$; Fig. 3C-E and Table II). Moreover, the area under curve (AUC) of PVT1 was 0.822 (95\% CI, 0.780-0.863), indicating a moderate diagnostic value of the PVT1 expression in $\mathrm{HCC}$ (Fig.3F). Furthermore, we investigated a different PVT1 expression in other clinical parameters of $\mathrm{HCC}$, but no positive results were found based on the TCGA database. In addition, we investigated the relationship between the PVT1 expression and patient survival. A low PVT1 expression was correlated with improved survival $(64.31 \pm 5.17$ months $)$ compared to the high PVT1 expression group $(59.59 \pm 4.75$ months, $\mathrm{P}=0.241$; Fig. 3G) in HCC.

Moreover, the Oncomine and GEPIA databases confirmed the high expression of PVT1 in HCC (Fig. 4A-C). Furthermore, GEPIA demonstrated that patients with a low PVT1 expression have improved overall and disease-free survival, consistent with the results in TCGA (Fig. 4D and E).

Target prediction and functional analysis. In the present study, 12 miRNA target prediction algorithms were utilized to predict the potential target genes of the four miRNAs. The genes predicted by $>6$ algorithms were selected as the final target genes. Among these target genes, 696 genes 


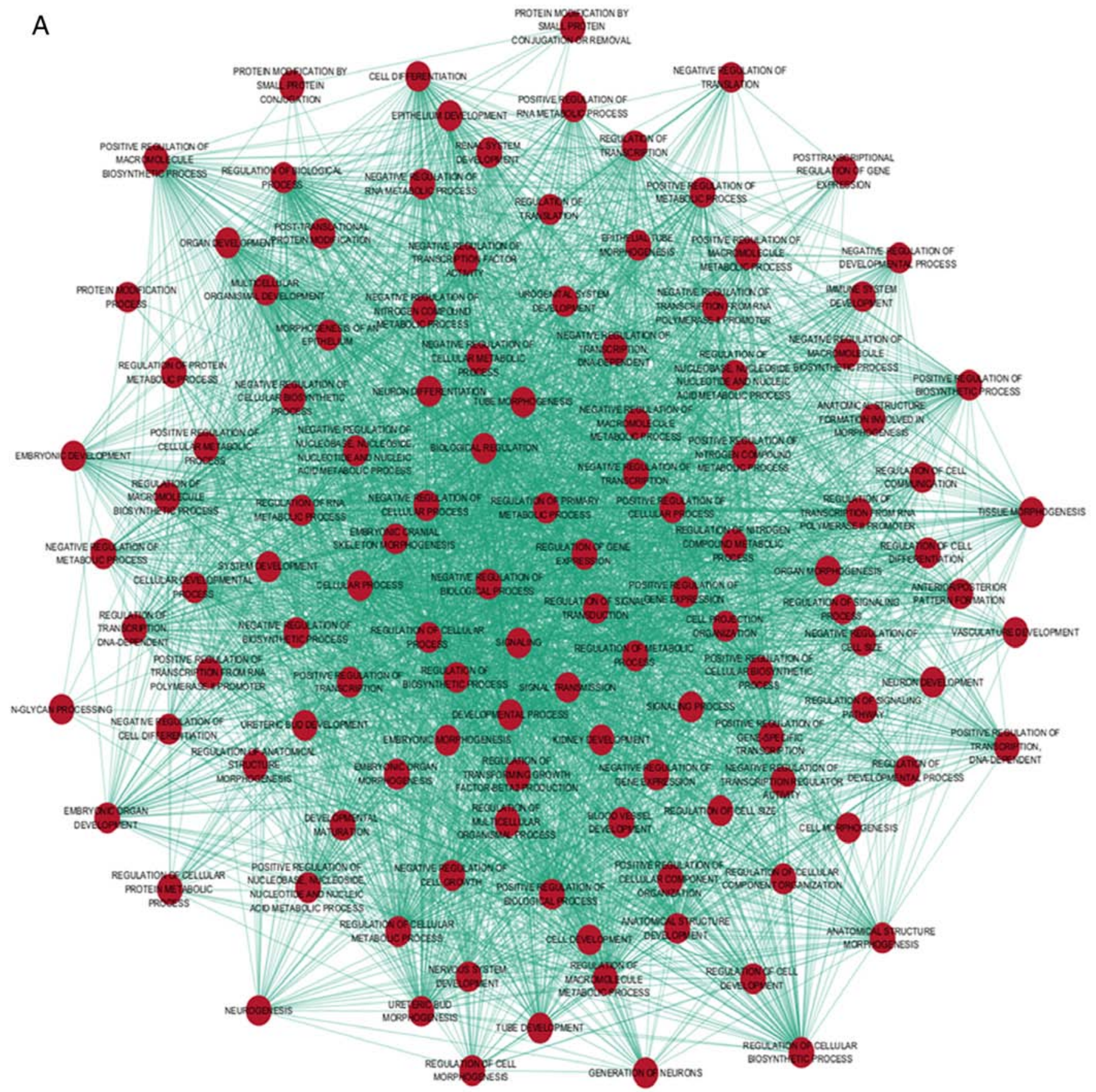

Figure 6. A functional network of Gene Ontology (GO) terms for the potential PVT1 genes in HCC. To further elucidate the functions of the overlapping genes, a function network was constructed according to Cytoscape.

were predicted by $>2$ miRNAs, and these 696 genes were used for the GO and pathway analyses (Fig. 5). The GO analysis indicated that the target genes were involved in complex cellular pathways, such as macromolecule biosynthetic process, compound metabolic process and transcription (Fig. 6 and Table III). The KEGG pathway analysis revealed that the MAPK and Wnt signaling pathways may be associated with regulation of the four candidate miRNAs (Table IV). To better identify the relationships between PVT1, miRNAs and target genes, a network was constructed via Cytoscape, and the genes were easily observed from the network (Fig. 7).
PPI network analysis. The STRING database was applied to construct the PPI network and 1,420 PPI pairs with a combined score of $<0.4$ were selected. PHLPP2 (degree, 42) and MAPK8 (degree, 26) had the highest degree and interactions in the PPI network. Then, a sub-network of 269 PPI pairs with $>20$ connectivity degrees was constructed for further analysis (Fig. 8). The number of nodes was 96, accounting for $13.79 \%$ of all the target genes. The clustering coefficient of PPI network was 0.634 , which indicates that the PPI network had high cluster properties.

In addition, the genes associated with the MAPK and Wnt signaling pathways were selected based on the 

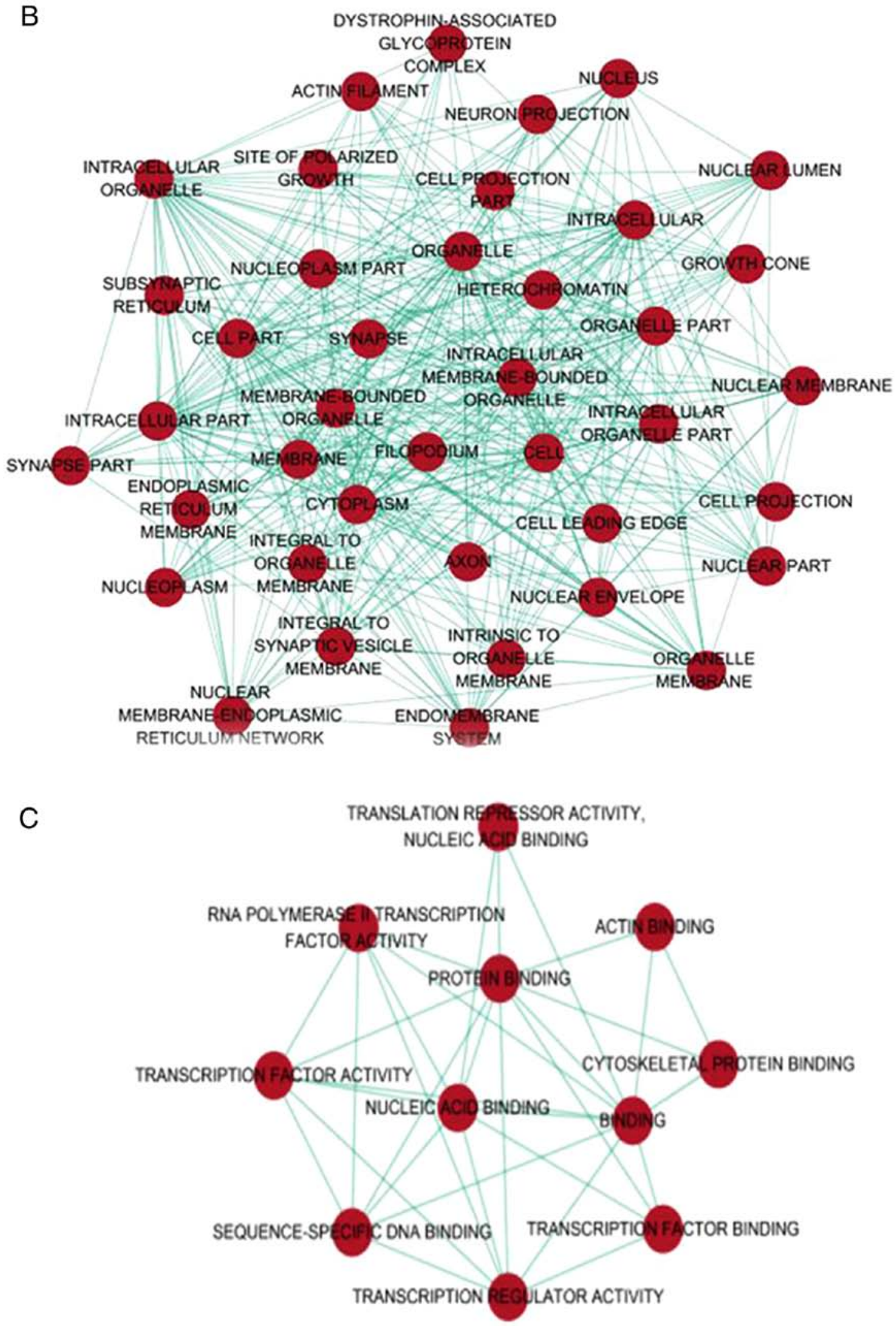

Figure 6. Continued.

KEGG pathway analysis. Five genes (PRKCA, MAPK8, $P P P 3 R 2, M A P 3 K 7$ and $P R K X)$ were overlapped based on the Venn diagrams. According to the degree of hub genes in PPI network, MAPK8 had a high degree (degree, 26).
Next, we investigated the preliminary expression level of the five genes based on TCGA, and the original expression data of $P P P 3 R 2$ was censored. Thus, based on TCGA, $M A P K 8$ and $P R K X$ were downregulated, whereas PRKCA 
Table IV. The top 10 KEGG pathways from the enrichment analysis of the target genes of miRNAs.

\begin{tabular}{|c|c|c|c|c|c|}
\hline KEGG ID & KEGG term & Count & $\begin{array}{l}\text { Fold } \\
\text { enrichment }\end{array}$ & P-value & Gene symbol \\
\hline hsa04010 & $\begin{array}{l}\text { MAPK signaling } \\
\text { pathway }\end{array}$ & 22 & 2.253 & 0.0006 & $\begin{array}{l}P R K C A, T A O K 1, T G F B R 1, P P P 3 R 2, S T K 4, \\
P R K X, T G F B 2, A T F 2, M A P 3 K 7, M A P K 1, \\
D U S P 4, R P S 6 K A 3, R A S G R F 2, E L K 4, \\
A R R B 1, M A P 3 K 2, M A P T, P D G F R A, M A P K 8, \\
\text { RAPGEF2, CACNA1B, RASA2 }\end{array}$ \\
\hline hsa04310 & Wnt signaling pathway & 15 & 2.716 & 0.0011 & $\begin{array}{l}\text { PRKCA, TBL1XR1, VANGL1, SMAD4, } \\
P P P 3 R 2, S M A D 3, F Z D 3, D A A M 1, F Z D 5, \\
P R K X, M A P 3 K 7, C C N D 1, P S E N 1, \text { PRICKLE2, } \\
\text { MAPK8 }\end{array}$ \\
\hline hsa04360 & Axon guidance & 13 & 2.755 & 0.0024 & $\begin{array}{l}\text { SEMA5A, ABLIM1, MAPK1, SEMA6A, } \\
\text { PLXNA2, NTN4, PPP3R2, ROBO2, EFNA5, } \\
\text { DPYSL2, SLIT1, SRGAP1, EPHA2 }\end{array}$ \\
\hline hsa05210 & Colorectal cancer & 10 & 3.255 & 0.0032 & $\begin{array}{l}\text { MAPK1, CCND1, TGFBR1, PDGFRA, SMAD4, } \\
\text { SMAD3, FZD3, MAPK8, FZD5, TGFB2 }\end{array}$ \\
\hline hsa05212 & Pancreatic cancer & 9 & 3.417 & 0.0043 & $\begin{array}{l}\text { MAPK1, CCND1, TGFBR1, SMAD4, RALA, } \\
\text { SMAD3, CDK6, MAPK8, TGFB2 }\end{array}$ \\
\hline hsa05200 & Pathways in cancer & 21 & 1.750 & 0.01500 & $\begin{array}{l}\text { PRKCA, XIAP, TGFBR1, MITF, SMAD4, } \\
\text { RUNX1T1, SMAD3, CDK6, EGLN1, FZD3, } \\
\text { FZD5, STK4, TPM3, TGFB2, MAPK1, CCND1, } \\
\text { HDAC2, CDKN2B, PDGFRA, RALA, MAPK8 }\end{array}$ \\
\hline hsa05220 & $\begin{array}{l}\text { Chronic myeloid } \\
\text { leukemia }\end{array}$ & 8 & 2.916 & 0.01856 & $\begin{array}{l}\text { MAPK1, CCND1, HDAC2, TGFBR1, SMAD4, } \\
\text { SMAD3, CDK6, TGFB2 }\end{array}$ \\
\hline hsa04520 & Adherens junction & 8 & 2.840 & 0.0212 & $\begin{array}{l}\text { MAP3K7, MAPK1, TGFBR1, SMAD4, SMAD3, } \\
P T P N 1, M L L T 4, V C L\end{array}$ \\
\hline hsa04120 & $\begin{array}{l}\text { Ubiquitin-mediated } \\
\text { proteolysis }\end{array}$ & 11 & 2.195 & 0.027 & $\begin{array}{l}\text { CUL3, UBE2D3, UBE4A, XIAP, NEDD4, } \\
U B E 2 K, U B E 2 G 1, U B A 2, U B E 2 J 1, U B E 2 W, \\
N E D D 4 L\end{array}$ \\
\hline hsa04144 & Endocytosis & 13 & 1.932 & 0.0350 & $\begin{array}{l}D N M 3, R A B 31, R A B 11 F I P 2, E R B B 4, T F R C, \\
N E D D 4, A R R B 1, T G F B R 1, P S D 3, P D G F R A, \\
E E A 1, N E D D 4 L, P I P 4 K 2 B\end{array}$ \\
\hline
\end{tabular}

KEGG, Kyoto Encyclopedia of Genes and Genomes.

and $M A P 3 K 7$ were upregulated in HCC compared to that in normal liver tissues (both $\mathrm{P}<0.05$, Fig. 9A-D). Furthermore, negative correlations were found between PVT1 and MAPK8 ( $r=-0.289, \mathrm{P}<0.001$, Fig. 9E), PRKCA ( $\mathrm{r}=-0.140$, $\mathrm{P}=0.007$, Fig. 9F) and MAP3K7 ( $\mathrm{r}=-0.084, \mathrm{P}=0.106$, Fig. 9G), whereas a positive correlation was found between PVT1 and PRKX (r=0.154, P=0.003, Fig. 9H). Moreover, based on HPA, weak staining in HCC was observed for MAPK8, whereas moderate staining was observed for PRKCA and PPP3R2 (Fig. 10A-F). Negative staining in both HCC and normal liver tissues was observed for MAP3K7, in contrast with its upregulated expression in TCGA (Fig. 10G and H), whereas moderate staining for PRKX was observed in $\mathrm{HCC}$, inconsistent with its downregulated expression in TCGA (Fig. 10I and J). Based on these results, PRKCA and MAPK8 were all negatively correlated with PVT1, whereas PRKCA was overexpressed in HCC, in contrast with the correlation of PVT1. Thus, only MAPK8 was selected. We hypothesized that PVT1 may influence MAPK8 expression in the MAPK or Wnt signaling pathways to participate in the different biological processes of HCC. However, the precise molecular mechanism of PVT1 in HCC needs further experimental investigation.

\section{Discussion}

Previous studies have demonstrated that lncRNAs participates in different biological processes, such as transcription, chromosome remodeling and post-transcriptional processing (35-37). Many studies have verified that lncRNAs are associated with the tumorigenesis and development of various types of cancer through various pathways, including the regulation of cell proliferation, metastasis and invasion (38-40). Thus, IncRNAs have opened an avenue of cancer genomics. 


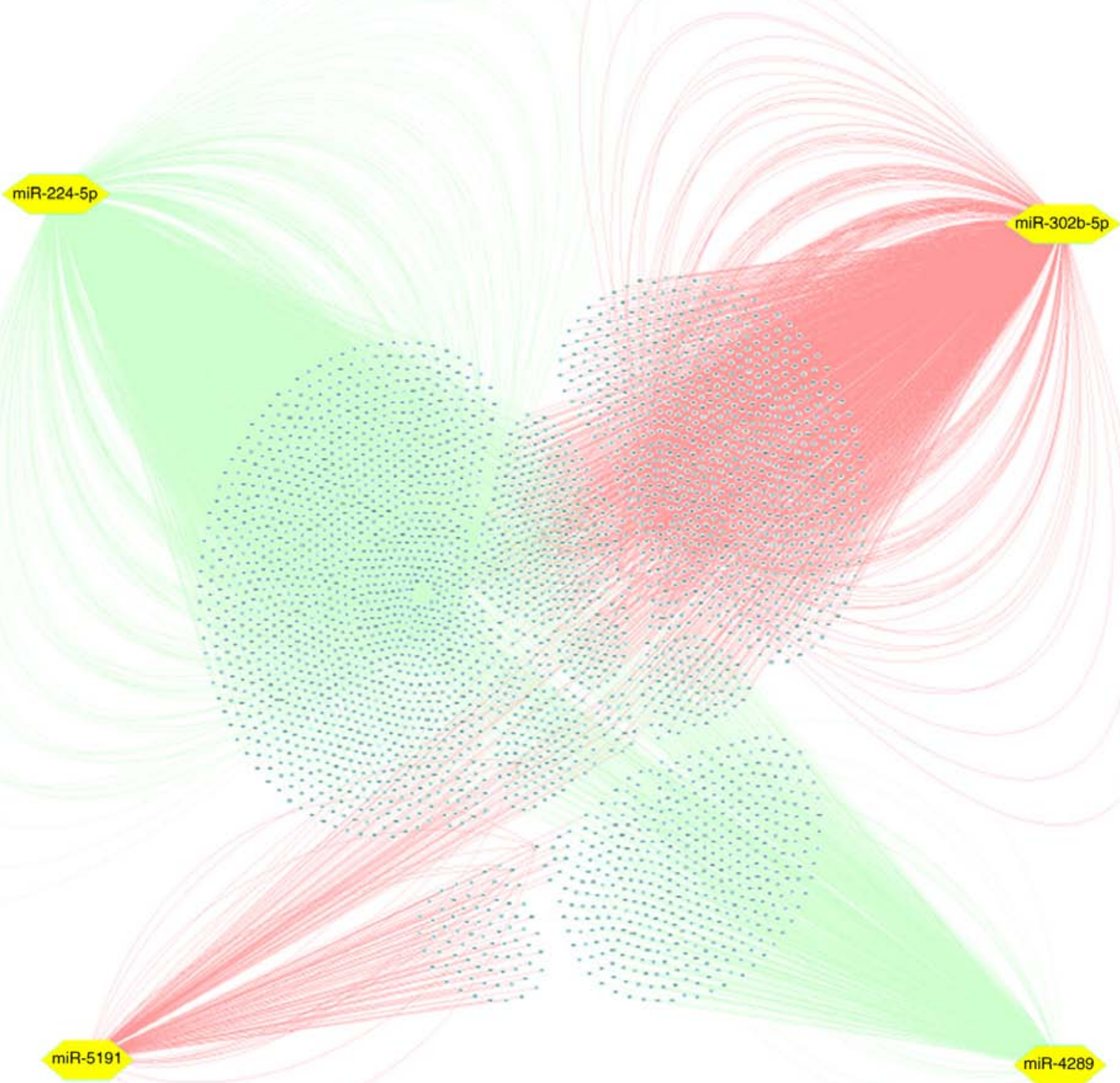

Figure 7. MiRNA-mRNA network constructed by Cytoscape. Four miRNAs were selected to draw the miRNA-mRNA network. Red indicates upregulation and green indicates downregulation.

To date, several studies have investigated the effect of PVT1 on various cancer types. Xu et al (41) demonstrated that PVT1 overexpression encouraged proliferation and invasion in gastric cancer cells via binding to FOXM1, and a high PVT1 expression was associated with the poor prognosis of gastric cancer patients. Chen et al (42) revealed that the overexpression of PVT1 promoted the invasion of non-small cell lung cancer cells. Additionally, PVT1 functioned as a competitive endogenous RNA to regulate the expression of MMP9 via competitively binding to microRNAs. Liu et al (43) showed that PVT1 was an oncogene in prostate cancer by activating miR-146a methylation to improve tumor growth. Nevertheless, the detailed roles for PVT1 in HCC remain undefinable. In the present study, we combined miRNA microarray analysis and TCGA, as well as Oncomine and GEPIA databases to explore the potential biological functions of PVT1 in HCC. We confirmed that PVT1 was an oncogene and highly expressed in HCC, consistent with Yu et al and Ding et al $(18,19)$. Moreover, Yu et al (18) revealed that the combined upregulation of two lncRNAs (PVT1 and uc002 mbe.2) offered a new method for the diagnosis of HCC, and the expression of these two IncRNAs was positively correlated with tumor size and clinical stage in HCC patients. Furthermore, Ding et al (19) revealed that the overexpression of PVT1 was strongly associated with the AFP level and could predict recurrence. By comparison, the present study showed that PVT1 expression was positively correlated with sex, ethnicity and pathological grade. The AUC of PVT1 indicated a moderate diagnostic value of PVT1 expression in HCC. Furthermore, the genetic alterations of PVT1 were observed in HCC based on TCGA, which may be correlated with the pathogenesis of HCC. 


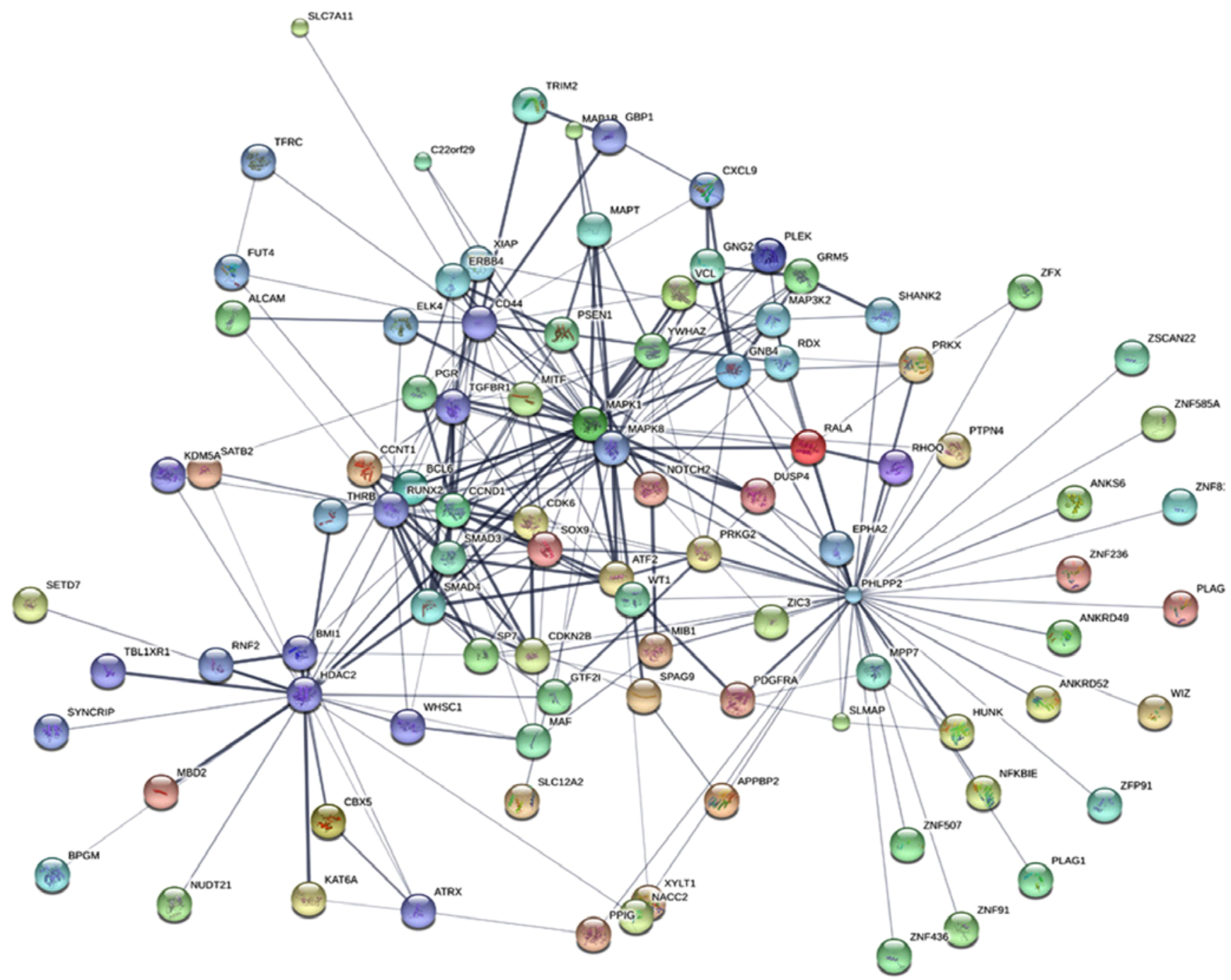

Nodes:

Network nodes represent proteins
splice isoforms or post-translational
modifications are collapsed, i.e.,
each node represents all the
proteins produced by a single,
protein-coding gene locus.

Node size
Small nodes:
protein of unknown $3 D$ structure
Large nodes:
some $3 D$ structure is known or
predicted

Node color
Colored nodes:
query proteins and first shell of
interactors
(5) White nodes:
second shell of interactors

Edges:

Edges represent protein-protein
associations
Associations are meant to be
specific and meaningful, i.e.
proteins jointly contribute to a
shared function; this does not
necessarily mean they are
physically binding each other.
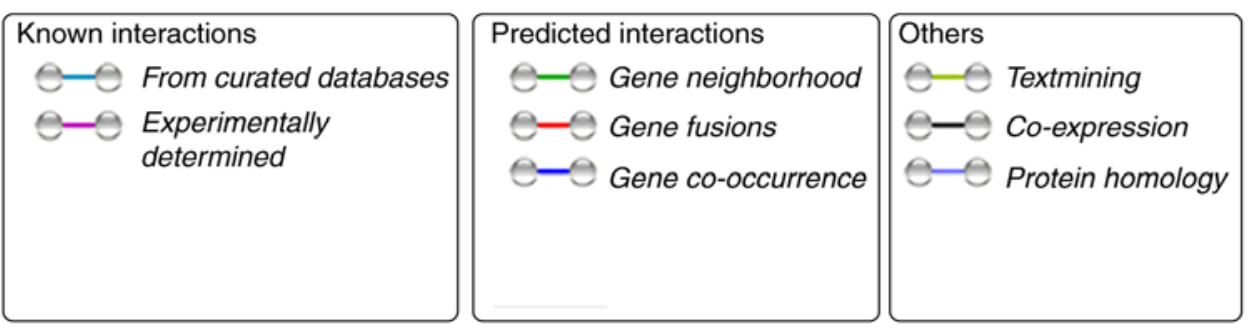

Figure 8. The PPI network of the target genes. The PPI network was constructed via STRING online and 269 PPI pairs were selected for further analysis.

To the best of our knowledge, the present study was the first to identify the differentially expressed miRNAs associated with PVT1 based on miRNA microarray analysis, and 12 miRNA target prediction algorithms were used to predict the underlying target genes of the differentially expressed miRNAs. According to GO analysis, the target genes were involved in complex cellular pathways, such as macromolecule biosynthetic process, compound metabolism, and transcription. The KEGG pathway analysis revealed that the MAPK and Wnt signaling pathways are potentially correlated with the regulation of the four candidate miRNAs. As reported, the MAPK and Wnt signaling pathways were all associated 

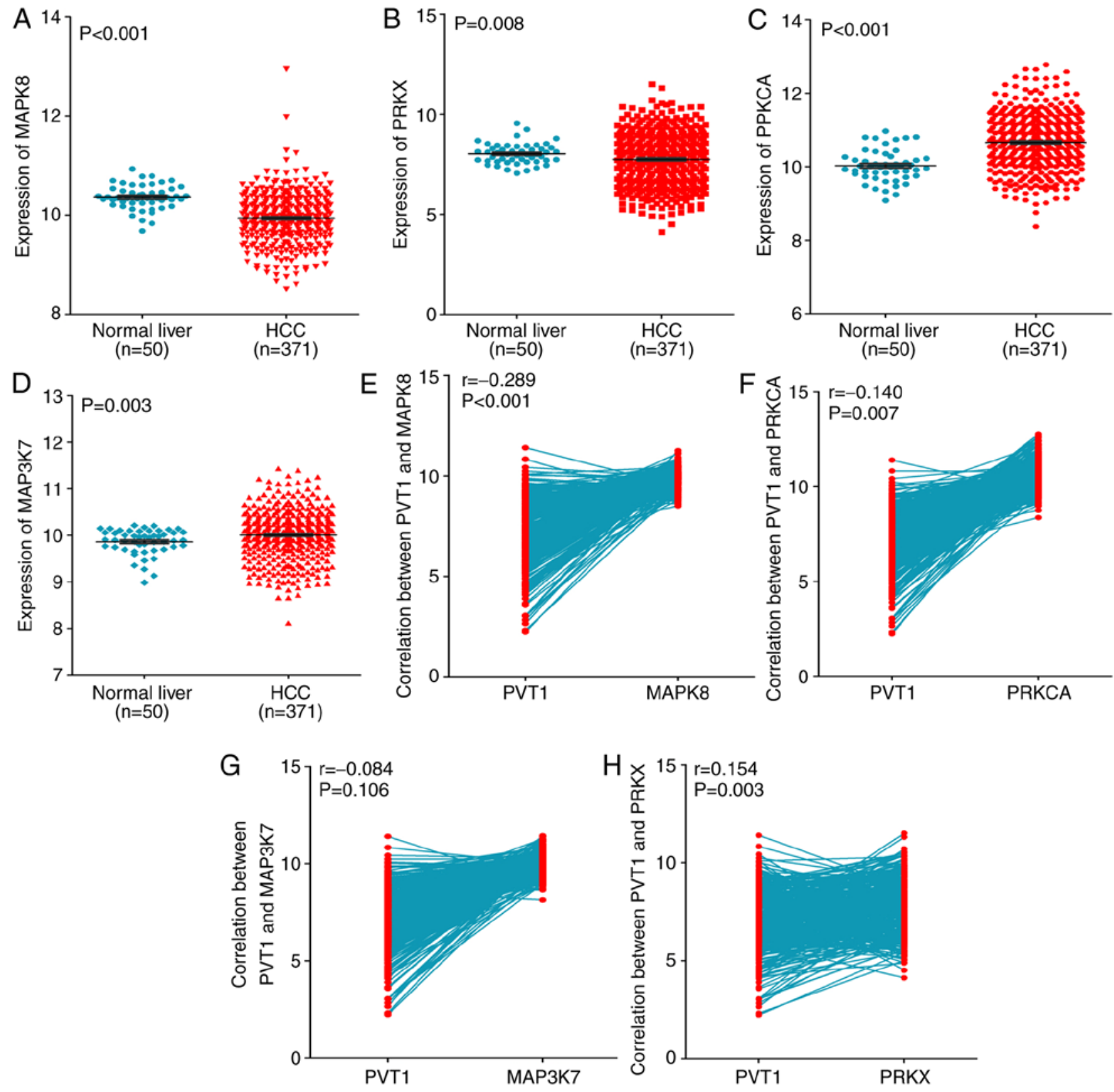

Figure 9. Clinical significance of the hub genes in HCC based on the TCGA database. Differential expression of (A) MAPK8, (B) PRKX, (C) PRKCA, and (D) MAP3K7 between HCC and non-cancerous liver tissue. (E) Negative correlation between PVT1 and MAPK8, (F) PVT1 and PRKCA, (G) PVT1 and MAP3K7, and (H) PVT1 and PRKX.

with proliferation, migration, invasion and prognosis and HCC (44-48). Consequently, we hypothesized that PVT1 plays a vital role in HCC by regulating the expression of the four miRNAs via the MAPK or Wnt signaling pathways, which requires further investigation on the precise molecular mechanism of PVT1 in HCC. We also investigated the genes from the MAPK and Wnt signaling pathways and the hub genes from PPI. We hypothesized that PVT1 may influence MAPK8 expression to contribute to different biological processes of HCC. Various in vitro and in vivo experiments, including cell proliferation, invasion and metastasis assays, and animal models, are needed to verify this hypothesis. The clinical significance and molecular mechanism of PVT1 in the biological function of $\mathrm{HCC}$ are to be further researched at the molecular, cellular, tissue and animal levels. Focusing on the new insight of PVT1 in HCC, the present study aimed to provide a potential biomarker or therapeutic target for HCC.

\section{Acknowledgements}

Not applicable.

\section{Funding}

The present study was financially supported through grants from the National Natural Science Foundation of China (no. NSFC81560489), the Natural Science Foundation of Guangxi, China (nos. 2016GXNSFBA380039 and 2017GXNSFAA198017) and the Promoting Project of Basic Capacity for Young and Middle-aged University Teachers in 

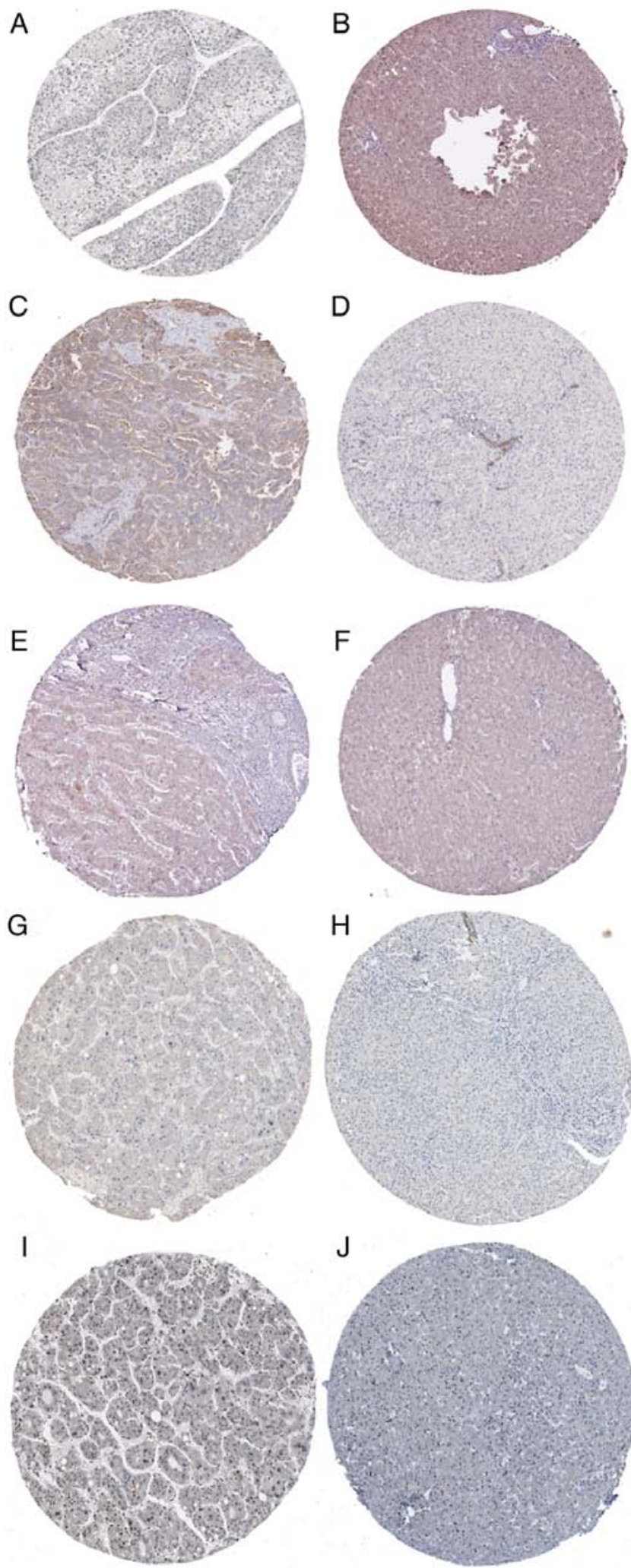

Figure 10. Validation of hub gene expression based on the HPA database (A) MAPK8 was weakly stained in HCC (magnification, x100), (B) MAPK8 was moderately stained in normal liver (magnification, x100), (C) PRKCA was moderately stained in HCC (magnification, x100), (D) PRKCA was weakly stained in normal liver (magnification, x100), (E) PPP3R2 was moderately stained in HCC (magnification, x100), (F) PPP3R2 was negatively stained in normal liver (magnification, x100), (G) MAP3K7 was negatively stained in HCC (magnification, x100), (H) MAP3K7 was negatively stained in normal liver (magnification, $\mathrm{x} 100$ ), (I) PRKX was moderately stained in HCC (magnification, $\mathrm{x} 100$ ), and (J) PRKX was negatively stained in normal liver (magnification, x100).
Guangxi (no. KY2016LX031) and Medical Excellence Award funded by the Creative Research Development grant from the First Affiliated Hospital of Guangxi Medical University.

\section{Availability of data and materials}

Data used in this study are available upon request to the corresponding author.

\section{Authors' contributions}

YZ and WM conceived and designed the study. XW, TZ and YQ performed the experiments. YZ and GC wrote the paper. DW and YD reviewed and edited the manuscript. All authors read and approved the manuscript and agree to be accountable for all aspects of the research in ensuring that the accuracy or integrity of any part of the work are appropriately investigated and resolved.

\section{Ethics approval and consent to participate}

All experimental protocols were approved by the First Affiliated Hospital of Guangxi Medical University (Nanning, China).

\section{Consent for publication}

Not applicable.

\section{Competing interests}

The authors DEC that they have no competing interests.

\section{References}

1. Li C, Miao R, Liu S, Wan Y, Zhang S, Deng Y, Bi J, Qu K, Zhang J and Liu C: Down-regulation of miR-146b-5p by long noncoding RNA MALAT1 in hepatocellular carcinoma promotes cancer growth and metastasis. Oncotarget 8: 28683-28695, 2017.

2. Lu PH, Chen MB, Liu YY, Wu MH, Li WT, Wei MX, Liu CY and Qin SK: Identification of sphingosine kinase 1 (SphK1) as a primary target of icaritin in hepatocellular carcinoma cells. Oncotarget 8: 22800-22810, 2017.

3. Maluccio $M$ and Covey A: Recent progress in understanding, diagnosing, and treating hepatocellular carcinoma. CA Cancer $\mathbf{J}$ Clin 62: 394-399, 2012.

4. Trépo C, Chan HL and Lok A: Hepatitis B virus infection. Lancet 384: 2053-2063, 2014

5. El-Serag HB: Hepatocellular carcinoma. N Engl J Med 365: 1118-1127, 2011.

6. Zhang H, Zhai Y, Hu Z, Wu C, Qian J, Jia W, Ma F, Huang W, Yu L, Yue W, et al: Genome-wide association study identifies 1p36.22 as a new susceptibility locus for hepatocellular carcinoma in chronic hepatitis B virus carriers. Nat Genet 42: 755-758, 2010.

7. Bréchot C: Pathogenesis of hepatitis B virus-related hepatocellular carcinoma: Old and new paradigms. Gastroenterology 127 (5 Suppl 1): S56-S61, 2004.

8. Xu Y, Qi Y, Luo J, Yang J, Xie Q, Deng C, Su N, Wei W, Shi D, $\mathrm{Xu}$ F, et al: Hepatitis B virus $\mathrm{X}$ protein stimulates proliferation, wound closure and inhibits apoptosis of $\mathrm{HuH}-7$ cells via $\mathrm{CDC} 42$. Int J Mol Sci 18: E586, 2017.

9. Moriguchi M, Takayama T, Higaki T, Kimura Y, Yamazaki S, Nakayama H, Ohkubo T and Aramaki O: Early cancer-related death after resection of hepatocellular carcinoma. Surgery 151: 232-237, 2012

10. Fairman J, Liu KH and Menne S: Prevention of liver tumor formation in woodchucks with established hepatocellular carcinoma by treatment with cationic liposome-DNA complexes. BMC Cancer 17: 172, 2017. 
11. Batista PJ and Chang HY: Long noncoding RNAs: Cellular address codes in development and disease. Cell 152: 1298-1307, 2013.

12. Xie X, Pan J, Wei L, Wu S, Hou H, Li X and Chen W: Gene expression profiling of microRNAs associated with UCA1 in bladder cancer cells. Int J Oncol 48: 1617-1627, 2016.

13. Sun XJ, Wang Q, Guo B, Liu XY and Wang B: Identification of skin-related lncRNAs as potential biomarkers that involved in Wnt pathways in keloids. Oncotarget 8: 34236-34244, 2017.

14. Zhu P, Wang Y, Wu J, Huang G, Liu B, Ye B, Du Y, Gao G, Tian Y, He L and Fan Z: LncBRM initiates YAP1 signalling activation to drive self-renewal of liver cancer stem cells. Nat Commun 7: 13608, 2016.

15. Cao C, Sun J, Zhang D, Guo X, Xie L, Li X, Wu D and Liu L: The long intergenic noncoding RNA UFC1, a target of MicroRNA 34a, interacts with the mRNA stabilizing protein $\mathrm{HuR}$ to increase levels of $\beta$-catenin in HCC cells. Gastroenterology 148: 415-426.e18, 2015

16. Zhou M, Zhang XY and Yu X: Overexpression of the long non-coding RNA SPRY4-IT1 promotes tumor cell proliferation and invasion by activating EZH2 in hepatocellular carcinoma. Biomed Pharmacother 85: 348-354, 2017.

17. Colombo T, Farina L, Macino G and Paci P: PVT1: A rising star among oncogenic long noncoding RNAs. Biomed Res Int 2015: $304208,2015$.

18. Yu J, Han J, Zhang J, Li G, Liu H, Cui X, Xu Y, Li T, Liu J and Wang C: The long noncoding RNAs PVT1 and uc002mbe.2 in sera provide a new supplementary method for hepatocellular carcinoma diagnosis. Medicine 95: e4436, 2016.

19. Ding C, Yang Z, Lv Z, DU C, Xiao H, Peng C, Cheng S, Xie H, Zhou L, Wu J and Zheng S: Long non-coding RNA PVT1 is associated with tumor progression and predicts recurrence in hepatocellular carcinoma patients. Oncol Lett 9: 955-963, 2015.

20. Wang F, Yuan JH, Wang SB, Yang F, Yuan SX, Ye C, Yang N, Zhou WP, Li WL, Li W and Sun SH: Oncofetal long noncoding RNA PVT1 promotes proliferation and stem cell-like property of hepatocellular carcinoma cells by stabilizing NOP2. Hepatology 60: 1278-1290, 2014.

21. Liu F, Yuan JH, Huang JF, Yang F, Wang TT, Ma JZ, Zhang L, Zhou CC, Wang F, Yu J, et al: Long noncoding RNA FTX inhibits hepatocellular carcinoma proliferation and metastasis by binding MCM2 and miR-374a. Oncogene 35: 5422-5434, 2016.

22. Zhu L, Yang N, Chen J, Zeng T, Yan S, Liu Y, Yu G, Chen Q, Du G, Pan W, et al: LINC00052 upregulates EPB41L3 to inhibit migration and invasion of hepatocellular carcinoma by binding miR-452-5p. Oncotarget 8: 63724-63737, 2017.

23. Xu X, Wang X, Fu B, Meng L and Lang B: Differentially expressed genes and microRNAs in bladder carcinoma cell line 5637 and T24 detected by RNA sequencing. Int J Clin Exp Pathol 8: 12678-12687, 2015

24. Subramanian Y, Kaliyappan K and Ramakrishnan KS: Facile hydrothermal synthesis and characterization of $\mathrm{Co}_{2} \mathrm{GeO}_{4}$ r-GO@C ternary nanocomposite as negative electrode for Li-ion batteries. J Colloid Interface Sci 498: 76-84, 2017.

25. Wei L, Murphy BL, Wu G, Parker M, Easton J, Gilbertson RJ, Zhang J and Roussel MF: Exome sequencing analysis of murine medulloblastoma models identifies WDR11 as a potential tumor suppressor in Group 3 tumors. Oncotarget 8: 64685-64697, 2017.

26. Chen F, Shen C, Wang X, Wang H, Liu Y, Yu C, Lv J, He J and Wen $\mathrm{Z}$ : Identification of genes and pathways in nasopharyngeal carcinoma by bioinformatics analysis. Oncotarget 8 : 63738-63749, 2017.

27. Bornstein S, Schmidt M, Choonoo G, Levin T, Gray J, Thomas CR Jr, Wong M and McWeeney S: IL-10 and integrin signaling pathways are associated with head and neck cancer progression. BMC Genomics 17: 38, 2016.

28. Zeng JH, Xiong DD, Pang YY, Zhang Y, Tang RX, Luo DZ and Chen G: Identification of molecular targets for esophageal carcinoma diagnosis using miRNA-seq and RNA-seq data from The Cancer Genome Atlas: A study of 187 cases. Oncotarget 8: 35681-35699, 2017.

29. Rhodes DR, Kalyana-Sundaram S, Mahavisno V, Varambally R, Yu J, Briggs BB, Barrette TR, Anstet MJ, Kincead-Beal C, Kulkarni P, et al: Oncomine 3.0: Genes, pathways, and networks in a collection of 18,000 cancer gene expression profiles. Neoplasia 9: 166-180, 2007.

30. Tang Z, Li C, Kang B, Gao G, Li C and Zhang Z: GEPIA: A web server for cancer and normal gene expression profiling and interactive analyses. Nucleic Acids Res 45: W98-W102, 2017.
31. Ashburner M, Ball CA, Blake JA, Botstein D, Butler H, Cherry JM, Davis AP, Dolinski K, Dwight SS, Eppig JT, et al: Gene ontology: Tool for the unification of biology. The Gene Ontology Consortium. Nat Genet 25: 25-29, 2000.

32. Ge QM, Huang CM, Zhu XY, Bian F and Pan SM: Differentially expressed miRNAs in sepsis-induced acute kidney injury target oxidative stress and mitochondrial dysfunction pathways. PLoS One 12: e0173292, 2017

33. Franceschini A, Szklarczyk D, Frankild S, Kuhn M, Simonovic M, Roth A, Lin J, Minguez P, Bork P, von Mering C and Jensen LJ: STRING v9.1: Protein-protein interaction networks, with increased coverage and integration. Nucleic Acids Res 41: D808-D815, 2013.

34. Qian Y, Feng L, Wu W, Weng T, Hu C, Hong B, Wang FX, Shen L, Wang Q, Jin X, et al: MicroRNA expression profiling of pancreatic cancer cell line L3.6p1 following B7-H4 knockdown. Cell Physiol Biochem 44: 494-504, 2017.

35. Shi X, Sun M, Liu H, Yao Y and Song Y: Long non-coding RNAs: A new frontier in the study of human diseases. Cancer Lett 339: 159-166, 2013.

36. Xiong DD, Feng ZB, Cen WL, Zeng JJ, Liang L, Tang RX, Gan XN, Liang HW, Li ZY, Chen G, et al: The clinical value of lncRNA NEAT1 in digestive system malignancies: A comprehensive investigation based on 57 microarray and RNA-seq datasets. Oncotarget 8: 17665-17683, 2017.

37. Chen Y, Xie H, Gao Q, Zhan H, Xiao H, Zou Y, Zhang F, Liu Y and Li J: Colon cancer associated transcripts in human cancers. Biomed Pharmacother 94: 531-540, 2017.

38. Zhang Z, Liu T, Wang K, Qu X, Pang Z, Liu S, Liu Q and Du J: Down-regulation of long non-coding RNA MEG3 indicates an unfavorable prognosis in non-small cell lung cancer: Evidence from the GEO database. Gene 630: 49-58, 2017.

39. Gao R, Zhang R, Zhang C, Zhao L and Zhang Y: Long noncoding RNA CCAT1 promotes cell proliferation and metastasis in human medulloblastoma via MAPK pathway. Tumori 0, 2017, doi: $10.5301 / \mathrm{tj} .5000662$

40. Jin L, Fu H, Quan J, Pan X, He T, Hu J, Li Y, Li H, Yang Y, Ye J, et al: Overexpression of long non-coding RNA differentiation antagonizing non-protein coding RNA inhibits the proliferation, migration and invasion and promotes apoptosis of renal cell carcinoma. Mol Med Rep 16: 4463-4468, 2017.

41. Xu MD, Wang Y, Weng W, Wei P, Qi P, Zhang Q, Tan C, Ni SJ, Dong L, Yang Y, et al: A positive feedback loop of lncRNA-PVT1 and FOXM1 facilitates gastric cancer growth and invasion. Clin Cancer Res 23: 2071-2080, 2017

42. Chen W, Zhu H, Yin L, Wang T, Wu J, Xu J, Tao H, Liu J and He X: lncRNA-PVT1 facilitates invasion through upregulation of MMP9 in nonsmall cell lung cancer cell. DNA Cell Biol 36: 787-793, 2017.

43. Liu HT, Fang L, Cheng YX and Sun Q: LncRNA PVT1 regulates prostate cancer cell growth by inducing the methylation of miR-146a. Cancer Med 5: 3512-3519, 2016.

44. Zeng J, Liu X, Li X, Zheng Y, Liu B and Xiao Y: Daucosterol inhibits the proliferation, migration, and invasion of hepatocellular carcinoma cells via $\mathrm{Wnt} / \beta$-catenin signaling. Molecules 22: E862, 2017.

45. Zhang J, Lai W, Li Q, Yu Y, Jin J, Guo W, Zhou X, Liu X and Wang Y: A novel oncolytic adenovirus targeting Wnt signaling effectively inhibits cancer-stem like cell growth via metastasis, apoptosis and autophagy in HCC models. Biochem Biophys Res Commun 491: 469-477, 2017.

46. Ou W, Lv J, Zou X, Yao Y, Wu J, Yang J, Wang Z and Ma Y: Propofol inhibits hepatocellular carcinoma growth and invasion through the HMGA2-mediated Wnt/beta-catenin pathway. Exp Ther Med 13: 2501-2506, 2017.

47. Peng $\mathrm{W}$ and Fan H: Long noncoding RNA CCHE1 indicates a poor prognosis of hepatocellular carcinoma and promotes carcinogenesis via activation of the ERK/MAPK pathway. Biomed Pharmacother 83: 450-455, 2016.

48. Lin W, Zhong M, Yin H, Chen Y, Cao Q, Wang C and Ling C: Emodin induces hepatocellular carcinoma cell apoptosis through MAPK and PI3K/AKT signaling pathways in vitro and in vivo. Oncol Rep 36: 961-967, 2016.

This work is licensed under a Creative Commons Attribution-NonCommercial-NoDerivatives 4.0 International (CC BY-NC-ND 4.0) License. 